\title{
Effects of Cassava Leaves Detoxification Processes on the Physicochemical and Sensory Qualities of Saka Saka
}

\author{
Bertin Mikolo, ", Aristide Herlyn Wilfrid Nakavoua ${ }^{2}$, Célestine Kiminou Nkounga ${ }^{1}$ \\ ${ }^{1}$ Laboratory of Agro-resource Valorization, National Polytechnic High School, Marien Ngouabi University, Brazzaville, Congo (RC) \\ ${ }^{2}$ Laboratory of Chemistry of Natural Substances (IRSEN), Brazzaville, Congo
}

\section{Email address:}

mikolobertin@yahoo.fr (B. Mikolo), a.nakavoua@lycee-saintexbrazza.org (A. H. W. Nakavoua),

celestine.kiminou@gmail.com (C. K. Nkounga)

${ }^{*}$ Corresponding author

\section{To cite this article:}

Bertin Mikolo, Aristide Herlyn Wilfrid Nakavoua, Célestine Kiminou Nkounga. Effects of Cassava Leaves Detoxification Processes on the Physicochemical and Sensory Qualities of Saka Saka. American Journal of Applied Chemistry. Vol. 9, No. 4, 2021, pp. 109-113.

doi: 10.11648/j.ajac.20210904.13

Received: July 19, 2021; Accepted: July 27, 2021; Published: August 5, 2021

\begin{abstract}
Cassava is a worldwide major source of food and energy, particularly in the countries of South America, Africa, and Asia. In Central Africa, saka saka is a major cassava leaf based dish. Because of their high toxicity due to cyanogen they contain, cassava leaves are diversely treated to prevent consumer intoxication. This work consisted in evaluating the main and interaction effects of three detoxification processes, washing, drying and bicarbonate treatment, on the quality of saka saka. For this purpose, the detoxification of the cassava leaves was performed following a complete factorial design of experiment. The treated material was used to prepare the saka saka dish which some physicochemical and sensual quality characteristics have been evaluated. The results have been treated by Analysis of Variance at 5\% significance level. The results showed that the bicarbonate treatment is the most efficient method to reduce the cyanogen content in the cassava leaves. All the three factors and their combinations have significant effects on the leaf $\mathrm{pH}$, lipids, ash and cyanide content and saka saka odor, color and taste. The combination of washing and drying is the most interesting as it is efficient, produces the most enjoyed dish and doesn't use chemical that can induce adverse effects to consumer.
\end{abstract}

Keywords: Cassava, Leaves, Detoxification, Experiment, Sensual

\section{Introduction}

Cassava is mainly known for its roots. However, the leaves are consumed as a vegetable in some countries as a source of protein and valuable nutrients [1-4]. In Congo, cassava leaves dishes are called saka-saka, or pondu in national languages. It is a specialty known in all the country's departments and is the national dish.

Because of their higher cyanogenic potential, cassava leaves are consumed much less than the roots [5]. Cyanogens are responsible for more or less serious intoxications that can lead to the death of consumers in case of defective detoxification [6].

The detoxification processes of cassava leaves are varied. In most cases, these leaves are ground and boiled, which significantly reduces their cyanide content [7]. However, the choice of less toxic varieties, metabolic control and fermentation, extraction by soaking, treatment with sodium bicarbonate or enzymes, hot drying and cooking are also being used [8-15]. The constant concern in investigating these methods is to effectively remove cyanides while preserving the values of nutritional and organoleptic characteristics.

The objective of this work is to evaluate the effect of the combination of detoxification methods on some quality characteristics of cassava leaves.

\section{Materials and Methods}

\subsection{Materials}

The bitter cassava leaves used were purchased at the Total market in Brazzaville. They were washed and ground in the laboratory in an aluminum mortar fitted with a pestle. The grindings were divided into 8 samples according to the 
experimental design below.

\subsection{Detoxification Tests}

\subsubsection{Design of the Experiment}

The detoxification of cassava leaves was carried out according to a full factorial design with three factors, each at two levels, in four replicates. The three factors were the treatment processes of washing (A), bicarbonate (B) and drying (C) all at lower -1 (no treatment) and upper 1 (treatment) levels. The design of this 8-trial design, whose matrix is shown in Table 1, was carried out using Minitab 17.3.1.

\subsubsection{Leaves Treatment}

The fresh cassava leaves have been detoxified by: washing, drying and treating with sodium bicarbonate [12, 14, 15]. Washing was performed by two successive washes of $300 \mathrm{~g}$ samples of shredded material with two $300 \mathrm{ml}$ fractions of distilled water. The water/crushed mixtures were wrung out after each wash through muslin. Bicarbonate detoxification was performed by mixing $300 \mathrm{~g}$ of sample with $1500 \mathrm{ml}$ of $0.4 \%$ sodium bicarbonate. Incubation was carried out for 3 min at room temperature, followed by $6 \mathrm{~h}$ in a water bath at $55^{\circ} \mathrm{C}$. Drying was carried out by drying $300 \mathrm{~g}$ samples of leaf crush at $50^{\circ} \mathrm{C}$ for $3 \mathrm{~h}$. Samples treated by the treatment appearing first in the combination were reprocessed by the next treatment (s). The trials were randomized.

\subsubsection{Cooking}

The 8 samples of $240 \mathrm{~g}$ for sensory evaluation, 7 treated and one control, each mixed with $8 \mathrm{~g}$ of salt and $20 \mathrm{~g}$ of corn oil in $200 \mathrm{ml}$ of water were cooked at $100^{\circ} \mathrm{C}$ for $1 \mathrm{~h} 30 \mathrm{~min}$.

\subsubsection{Evaluation of Physicochemical Characteristics of Raw Samples}

\section{(i) PH Measurement}

The $\mathrm{pH}$ values were read by pricking the electrode of the pH-meter directly into the sample.

\section{(ii) Determination of Ash Content}

The ash contents were determined by incineration [16]. A 2 $\mathrm{g}$ mass of each sample, oven-dried at $50^{\circ} \mathrm{C}$ for $24 \mathrm{~h}$ and contained in a crucible of previously determined mass, was calcined in a muffle furnace at $550^{\circ} \mathrm{C}$ for $8 \mathrm{~h}$. The ash content was expressed by the following formula (1):

$$
\operatorname{Ash}(\%)=\frac{m_{2}-m_{0}}{m_{1}-m_{0}} \times 100
$$

where $m_{0}$ is the empty weight of the crucible, in grams, $m_{1}$ is the weight of the crucible plus the sample and, $m_{2}$ is the weight of the crucible plus the ash.

\section{(iii) Determination of Total Lipids}

The estimation of total lipids was performed in the Soxhlet following the procedure. Dried samples of $10 \mathrm{~g}$, previously dried, were used as extraction matrices. The extract solvent was evaporated under reduced pressure and the residue weighed. The total lipid content was expressed as a percentage per $100 \mathrm{~g}$ of dry matter.

\section{(iv) Determination of Cyanides}

The cyanides were determined by the titrimetric method [17]. For this purpose, a treated or untreated (control) sample of $20 \mathrm{~g}$ of shredded material was transferred to a flask and mixed with $200 \mathrm{ml}$ of distilled water. The mixture was distilled to $150 \mathrm{ml}$ of distillate. A volume of $20 \mathrm{ml}$ of $0.02 \mathrm{M}$ $\mathrm{NaOH}$ was added to the distillate and the mixture made up to $250 \mathrm{ml}$ with distilled water. Three samples, two at $100 \mathrm{ml}$ and one at $50 \mathrm{ml}$ were prepared. To each of the $100 \mathrm{ml}$ samples were added $8 \mathrm{ml}$ of $6 \mathrm{M}$ ammonia and $2 \mathrm{ml}$ of $5 \%$ $\mathrm{KI}$; to the $50 \mathrm{ml}$ sample $4 \mathrm{ml}$ and $1 \mathrm{ml}$ of the same products. The samples were titrated with $0.2 \mathrm{M}$ silver nitrate $\mathrm{AgNO}_{3}$ using the $50 \mathrm{ml}$ sample as a test. The percentage of cyanides was estimated by the following formula ( 2 and 3 ).

In ppm:

$$
Q H C N=V_{\text {Titrage }} \times 1.08
$$

In mg / Kg:

$$
Q H C N=\frac{\mathrm{QHCN}(\mathrm{ppm}) \times 1000}{20}
$$

With the QHCN quantity of hydrocyanic acid

\subsubsection{Assessment of Sensory Characteristics}

The saka saka samples were evaluated for color, odor and taste by a panel of inexperienced assessors recruited from the ENSP students. The assessors were each given the eight samples, paper towels, a glass of mineral water, eight spoons, biscuits and an evaluation sheet shown in the annex. They were asked to taste and rate the samples on a hedonic scale ranging from 1 (don't like extremely) to 9 (like extremely).

\subsubsection{Data Analysis}

Some data were transformed into natural logarithms (ln), in order to obtain the highest correlation values. They were analyzed by graphs and analysis of variance using Minitab software at the 5\% significance level. The effects were considered significant for values of $\mathrm{P}<0.05$.

\section{Results}

\subsection{Effects on Physicochemical Characteristics of Treated Cassava Leaves}

\subsection{1. $\mathrm{PH}$}

The $\mathrm{pH}$ data of the different samples are shown in Table 1 along with the effect estimates and p-values for each individual term and interaction. The $\mathrm{p}$-values indicate that two main effects, bicarbonate $(\mathrm{p}=0.0230)$ and washing $(\mathrm{p}=0.0190)$ and a bicarbonate*drying interaction $(\mathrm{p}=0.0050)$ are significant. The largest effect equal to 3.1158 is obtained with bicarbonate, which increases the $\mathrm{pH}$; while the other factors tend to decrease it. The effect of the three factors combination is not significant.

It can be seen that only bicarbonate has a significant positive effect on the ash content. The percentage of ash increases when bicarbonate increases from level -1 to level 1. The effects of the other two variables and the interactions are 
not significant.

Table 1. PH data of cassava leaves.

\begin{tabular}{lllllllll}
\hline Trial & $\mathbf{( 1 )}$ & $\mathbf{a}$ & $\mathbf{b}$ & $\mathbf{c}$ & $\mathbf{a b}$ & $\mathbf{a c}$ & $\mathbf{b c}$ & $\mathbf{a b c}$ \\
\hline 1 & 6.45 & 5.61 & 9.74 & 6.29 & 9.44 & 6.04 & 9.05 & 9.52 \\
2 & 6.51 & 6.22 & 10.18 & 6.49 & 9.1 & 6.39 & 8.74 & 9.35 \\
3 & 6.44 & 5.84 & 9.65 & 6.3 & 9.47 & & 8.83 & \\
4 & 6.18 & 6.15 & & 6.34 & 9.18 & & 9.52 \\
5 & & 5.65 & & & & & -0.2842 & 0.12 \\
Effect & & -0.2271 & 3.1158 & -0.2204 & 0.1742 & 0.2429 & 0.0050 \\
P-Value & & 0.0190 & 0.0000 & 0.0230 & 0.0660 & 0.0130 & 0.1360 \\
\hline
\end{tabular}

Table 2. Percentage of total lipids per dry mass of cassava leaves.

\begin{tabular}{|c|c|c|c|c|c|c|c|c|}
\hline Trial & (1) & $\mathbf{a}$ & b & c & $\mathbf{a b}$ & ac & bc & abc \\
\hline 1 & 10.4 & 10.6 & 11.7 & 11 & 7.6 & 8.6 & 9 & 7.6 \\
\hline 2 & 10 & 8.9 & 8.6 & 10.8 & 10.7 & 10.8 & 9.1 & 6.3 \\
\hline 3 & 8.1 & 8.8 & 10.4 & & 8.8 & 8 & 11.1 & 5.6 \\
\hline 4 & 12.3 & 7.4 & & & 7.5 & 8.4 & & \\
\hline Effect & & -1.594 & -0.548 & -0.065 & 0.019 & -0.165 & -0.427 & 0.173 \\
\hline P-value & & 0.015 & 0.368 & 0.915 & 0.975 & 0.785 & 0.481 & 0.774 \\
\hline
\end{tabular}

Table 3. Ash percentages in cassava leaves samples.

\begin{tabular}{|c|c|c|c|c|c|c|c|c|}
\hline Trial & (1) & $\mathbf{a}$ & $\mathbf{b}$ & c & $\mathbf{a b}$ & ac & bc & abc \\
\hline 1 & 7.4 & 4.6 & 7 & 2.03 & 8.2 & 4 & 7 & 4.8 \\
\hline 2 & 2.38 & 3.89 & 8.59 & 6.57 & 8.38 & 6.25 & 8.14 & 6.75 \\
\hline 3 & 5.54 & 0 & & & 5.81 & 3.33 & 6.36 & 4.51 \\
\hline 4 & 4.62 & 0 & & & 6.73 & & & \\
\hline Effect & & -1.241 & 2.915 & -0.209 & 0.077 & 0.448 & -1.069 & -1.097 \\
\hline $\mathrm{P}$ Value & & 0.120 & 0.001 & 0.786 & 0.920 & 0.562 & 0.176 & 0.166 \\
\hline
\end{tabular}

Table 4. Cyanide content in samples.

\begin{tabular}{|c|c|c|c|c|c|c|c|c|}
\hline Term & (1) & $\mathbf{a}$ & $\mathbf{b}$ & c & $\mathbf{a b}$ & ac & bc & abc \\
\hline 1 & 64.6 & 27 & 21.6 & 27 & 10.8 & 13.5 & 16.2 & 13.5 \\
\hline 2 & 116.1 & 40.5 & 48.6 & 21.6 & 21.6 & 18.9 & 21.6 & 8.64 \\
\hline 3 & 94.5 & 27 & 21.6 & 37.8 & 32.4 & 42.3 & 10.8 & 10.8 \\
\hline Effect & - & -19.59 & -23.64 & -24.39 & 15.03 & 12.48 & 11.13 & -13.14 \\
\hline P Value & - & 0.002 & 0.001 & 0 & 0.014 & 0.036 & 0.058 & 0.028 \\
\hline
\end{tabular}

\subsubsection{Lipids}

The values of the total lipid contents and the results of the effect analysis are shown in Table 2 . It can be seen that only the washing factor has a significant negative effect. The lipid level decreases when the washing is changed from level -1 to level 1, with a negative effect of $-1.594 \mathrm{p}=(0.015)$. The effects of the other factors and interactions are not significant $(\mathrm{p}>0.05)$.

\subsubsection{Ash}

The ash contents of the different cassava leaf samples their corresponding effect analysis are shown in Table 3 . It varies from 0 to 8 . It is found that only bicarbonate has a significant positive effect on the ash content $(p=0.001)$. The percentage of ash increases when the bicarbonate goes from level -1 to level 1 . The effects of the other two variables and interactions are not significant.

\subsubsection{Cyanides}

The values of the cyanide percentages and the results of the effects analysis are shown in Table 4 show that all the main effects and interactions are significant $(p<0.05)$. The three main effects of washing, bicarbonate and drying negatively influence the level of cyanides. The greatest effect was seen for the bicarbonate treatment, followed by drying and washing. The effect of the washing * drying interaction is greater than that of the other interactions.

\subsection{Effects of Cassava Leaves Detoxification Processes on Color, Odor and Taste of Saka Saka}

The color, odor and taste rate data for saka saka samples prepared from cassava leaves detoxified by different processes individually and in combination are shown in Tables 4, 5 and 6. The columns are not of equal length because outliers were removed after the analyses of the raw data.

\subsubsection{Effects on Color}

The results of the analysis of variance, presented in Table 5, show that all three factors and the two- and three-factor interactions have significant effects on the characteristic color. All $\mathrm{P}$ values are equal to $0.000<0.05$. Positive effects are obtained with the drying factor and the three two-factor interactions. The main effects of the other factors and the three-factor interaction (Wash*Bicarbonate*Drying) are 
negative.

\subsubsection{Effects on Odor}

For the odor characteristic, only two factors (bicarbonate and drying) and one two-factor interaction (Bicarbonate*Drying) have negative significant effects. For the other factors and interactions, the corresponding $\mathrm{p}$ values are above the 5\% significance level for the other factors and interactions. Their effects are therefore not significant (Table 6).

\subsubsection{Effects on Taste}

The examination of the results presented in Table 7 of the analysis of variance shows that all main effects and interactions are significant; all $\mathrm{P}$ values are less than 0.05 . The effects are negative for washing and the interactions bicarbonate*drying and washing*drying*bicarbonate and positive for the rest of the factors and interactions.

Table 5. Rate data for color.

\begin{tabular}{|c|c|c|c|c|c|c|c|c|}
\hline Trial & (1) & a & $\mathbf{b}$ & c & $\overline{a b}$ & $\overline{a c}$ & $\overline{b c}$ & abc \\
\hline 1 & 6 & 8 & 6 & 5 & 4 & 7 & 4 & 6 \\
\hline 2 & 6 & 8 & 7 & 6 & 2 & 8 & 5 & 6 \\
\hline 3 & 6 & 6 & 7 & 7 & 3 & 8 & 5 & 5 \\
\hline 4 & 6 & 6 & 8 & 5 & 2 & 8 & 5 & 6 \\
\hline 5 & 7 & 7 & 6 & 6 & 4 & 8 & 4 & 6 \\
\hline 6 & 7 & 7 & 7 & 5 & 2 & 8 & 6 & \\
\hline 7 & 6 & 6 & 7 & 6 & 2 & 8 & 5 & \\
\hline 9 & & & 7 & & & & & \\
\hline Effect & & -0.1385 & -0.4055 & 0.1738 & 0.4285 & 0.1702 & 0.2897 & -0.4055 \\
\hline p-value & & 0.000 & 0.000 & 0.000 & 0.000 & 0.000 & 0.000 & 0.000 \\
\hline
\end{tabular}

Table 6. Rate data for odor.

\begin{tabular}{|c|c|c|c|c|c|c|c|c|}
\hline Trial & (1) & $\mathbf{a}$ & b & c & $\mathbf{a b}$ & ac & bc & abc \\
\hline 1 & 6 & 4 & 6 & 4 & 6 & 7 & 4 & 6 \\
\hline 2 & 6 & 5 & 6 & 5 & 6 & 6 & 4 & 4 \\
\hline 3 & 5 & 6 & 5 & 4 & 6 & 5 & 6 & 4 \\
\hline 4 & 7 & 6 & 7 & 6 & 6 & 6 & 5 & 5 \\
\hline 5 & 7 & 6 & 7 & 6 & 6 & 7 & 4 & 5 \\
\hline 6 & 5 & 5 & 5 & 6 & 5 & 7 & 5 & 5 \\
\hline 7 & 6 & 6 & 6 & 6 & & 6 & 6 & 6 \\
\hline 9 & & 5 & & 6 & & & & \\
\hline Effect & & -0.0017 & -0.1027 & -0.0757 & 0.004 & 0.0502 & -0.112 & -0.0246 \\
\hline $\mathrm{P}$ - value & & 0.96 & 0.004 & 0.031 & 0.907 & 0.147 & 0.002 & 0.474 \\
\hline
\end{tabular}

Table 7. Rate data for taste.

\begin{tabular}{|c|c|c|c|c|c|c|c|c|}
\hline Trial & (1) & $\mathbf{a}$ & $\mathbf{b}$ & C & $\mathbf{a b}$ & ac & bc & abc \\
\hline 1 & 6 & 3 & 6 & 4 & 6 & 7 & 5 & 4 \\
\hline 2 & 6 & 8 & 2 & 2 & 4 & 6 & 5 & 7 \\
\hline 3 & 5 & 7 & 4 & 5 & 5 & 8 & 6 & 5 \\
\hline 4 & 7 & 3 & 7 & 6 & 2 & 4 & 6 & 5 \\
\hline 5 & 6 & 9 & 5 & 6 & 4 & 8 & 5 & 5 \\
\hline 6 & 6 & 2 & 3 & 5 & 7 & 6 & 6 & \\
\hline 7 & 4 & 3 & 2 & 8 & 7 & 7 & 7 & \\
\hline 8 & 7 & & 3 & & & & & \\
\hline 9 & & & 6 & & & & & \\
\hline Effect & & -0.1712 & 0.1225 & 0.0889 & 0.1045 & 0.1568 & -0.2678 & -0.2544 \\
\hline P-value & & 0.000 & 0.004 & 0.031 & 0.012 & 0.000 & 0.000 & 0.000 \\
\hline
\end{tabular}

\section{Conclusion}

From the results obtained, it appears that the treatment of cassava leaves by washing, drying, bicarbonate or combinations of these processes, influence the values of the quality characteristics of saka saka. The average cyanide level is reduced from 91.7 in the control to between 42 and $10 \mathrm{mg} / \mathrm{kg}$ in the treated samples. All three factors and their interactions have significant negative effects on cyanide levels. Bicarbonate has a greater effect than drying and washing. Other authors have obtained similar results $[12,14$, 15]. The only differences observed are in the amounts of cyanides which were determined by different methods. Otherwise, bicarbonate remains the most important detoxification factor, followed by drying.

The $\mathrm{pH}$ values are also affected by the treatments. While the control has a value of 5.66, the $\mathrm{pH}$ is more acidic (less than 5) in the samples treated by drying and more basic (more than 8) in those treated with bicarbonate. The 
percentage of lipids decreases when the washing goes from the lower to the higher level, while the percentage of ash increases when the bicarbonate factor goes from the lower to the higher level.

The results obtained show that all the tested detoxification factors and their interactions have significant effects on three sensual quality characteristics (color, odor and taste) of the cassava leaf product which is saka saka. The most important interactions are two-factor interactions among which the washing*drying interaction gives positive effects on all characteristics.

At the present stage of this work, we believe that washdrying, which gives the product most appreciated by consumers, can be retained as a detoxification procedure. Although carbonate has a greater effect on cyanide reduction, it gives saka saka that is less appreciated by panelists. The other two factors also have significant negative effects on the cyanide characteristic. Even if the cyanide reduction is less with these two methods, the remaining cyanides could be significantly reduced during cooking. In addition, these two methods can better guarantee the safety of consumers than bicarbonate, which is a chemical product.

Detoxification by two-level factors made it possible to identify the factors with significant effects. However, experimentation with several level factors should make it possible to optimize the quality of saka saka.

\section{References}

[1] Ufuan Achidi, A., Ajayi, O. A., Bokanga, M., \& MaziyaDixon, B. (2005). The use of cassava leaves as food in Africa. Ecology of Food and Nutrition, 44 (6), 423-435.

[2] Wobeto, C., Corrêa, A. D., Abreu, C. M. P. D., Santos, C. D. D., \& Abreu, J. R. D. (2006). Nutrients in the cassava (Manihot esculenta Crantz) leaf meal at three ages of the plant. Food Science and Technology, 26 (4), 865-869.

[3] Latif, S., \& Müller, J. (2015). Potential of cassava leaves in human nutrition: a review. Trends in Food Science \& Technology, 44 (2), 147-158.

[4] Oresegun, A., Fagbenro, O. A., Ilona, P., \& Bernard, E. (2016) Nutritional and anti-nutritional composition of cassava leaf protein concentrate from six cassava varieties for use in aqua feed. Cogent Food \& Agriculture, 2 (1), 1147323.

[5] Nhassico, D., Muquingue, H., Cliff, J., Cumbana, A., \& Bradbury, J. H. (2008). Rising African cassava production, diseases due to high cyanide intake and control measures.
Journal of the Science of Food and Agriculture, 88 (12), 20432049.

[6] Roger A. Coulombe, Jr., 2001. Natural Toxins and Chemopreventives in Plants. In Food Toxicology, CRC Press LLC, pp: 143-167.

[7] Ngudi, D. D., Kuo, Y. H., \& Lambein, F. (2003). Cassava cyanogens and free amino acids in raw and cooked leaves. Food and Chemical Toxicology, 41 (8), 1193-1197.

[8] Obadina A., (2009). Microbial detoxification of cassava leaves. Abstracts / Toxicology Letters 189S S57-S273.

[9] Nambisan, B. (2011). Strategies for elimination of cyanogens from cassava for reducing toxicity and improving food safety. Food and chemical toxicology, 49 (3), 690-693.

[10] Vouidibio Mbozo, A. B., Kobawila, S. C., Anyogu, A., Awamaria, B., Louembe, D., Sutherland, J. P., \& Ouoba, L. I. I. (2017). Investigation of the diversity and safety of the predominant Bacillus pumilus sensu lato and other Bacillus species involved in the alkaline fermentation of cassava leaves for the production of Ntoba Mbodi. Food Control, 82, 154162.

[11] Safa, Z. J., Aminzadeh, S., Zamani, M., \& Motallebi, M. (2017). Significant increase in cyanide degradation by Bacillus sp. M01 PTCC 1908 with response surface methodology optimization. AMB Express, 7 (1), 200.

[12] Bradbury, J. H., \& Denton, I. C. (2011). Mild methods of processing cassava leaves to remove cyanogens and conserve key nutrients. Food Chemistry, 127 (4), 1755-1759.

[13] Hawashi, M., Sitania, C., Caesy, C., Aparamarta, H. W., Widjaja, T., \& Gunawan, S. (2019). Kinetic data of extraction of cyanide during the soaking process of cassava leaves. Data in brief, 25, 104279.

[14] Latif, S., Zimmermann, S., Barati, Z., \& Müller, J. (2019). Detoxification of Cassava Leaves by Thermal, Sodium Bicarbonate, Enzymatic, and Ultrasonic Treatments. Journal of food science, 84 (7), 1986-1991.

[15] Junior, E. N. M., Chisté, R. C., \& da Silva Pena, R. (2019). Oven drying and hot water cooking processes decrease HCN contents of cassava leaves. Food Research International, 119, 517-523.

[16] Huppertz, T. (2012). Determination of the Ash Content. In Analytical Methods for Food and Dairy Powders, 113-118.

[17] Gervason, M. A., Olela, B. O., Waiganjo, B. W., Wakori, E. W., \& Onyancha, J. M. (2017). Evaluation of Cyanide Levels in Two Cassava Varieties (Mariwa and Nyakatanegi) Grown in Bar-agulu, Siaya County, Kenya. Journal of Food and Nutrition Research, 5 (11), 817-823. 